\title{
VULNERABILITY OF AGRICULTURAL AREAS TO CLIMATIC RISK AND EFFECTIVENESS OF RISK MANAGEMENT POLICY SCHEME IN ITALY
}

\author{
A. PONTRANDOLFI ${ }^{1}$, F. CAPITANIO ${ }^{2}$ \& A.G. PEPE ${ }^{1}$ \\ ${ }^{1}$ Council for Agricultural Research and Economics, Italy \\ ${ }^{2}$ University of Naples Federico II, Italy
}

\begin{abstract}
At the global level, risk management tools are under discussion, in particular in the agricultural sector, in relation to its vulnerability to climatic risk. The main question points refer to the effectiveness of the most common current policy schemes, based on public support to insurances and compensation aids, in relation to the patterns of risk analysis in the context of climate change. Italy has a long tradition of risk management in agriculture because of the heterogeneity of climatic conditions. The present study has been conducted by Council for Agricultural Research and Economics to explore the potential of the current risk management scheme. One of the more relevant aspects studied is the demand for risk management in terms of exposure to disasters of the agricultural areas and their vulnerability. Crossing this analysis with the policy scheme, it is possible to assess its effectiveness in covering climatic risks. The results show that the current system based on economic tools needs a strong integration into a wider framework of risk assessment and policy strategies addressing climate change adaptation, in synergy with other structural and management measures.

Keywords: agriculture and climate change, climatic risk management, insurance schemes, policy assessment.
\end{abstract}

\section{CONTEXT AND OBJECTIVES OF THE STUDY}

The climatic scenarios currently taking shape show an increase in uncertainty of climate conditions directly influencing the agricultural production. Within the studies of the Intergovernmental Panel on Climate Change (IPCC) [1], the sector is indeed one of the most exposed and vulnerable to climate change, in particular referring to the higher likelihood of weather events leading to natural disasters.

Italian agricultural production is based on the quality and variety of production, and also linked to the heterogeneous environmental conditions of the territory, therefore, the weather and climate conditions have always represented an important factor in the management of farms. Referring to the risk of disasters linked to adverse weather events, it is active from 1970s, the National Solidarity Fund for natural disasters in agriculture, reformed in 2004 (decree 102/2004).

In the last decades, the conditions quickly changed with climate change impacts, in particular the most important elements for agriculture include the increase of temperatures, the different patterns of precipitations, the increase of extreme weather phenomena. For these reasons, according to the scientific literature elaborated by the IPCC [2], in assessing risk in agriculture, it is important to consider the new concept of 'climate risk', resulting from 
climate change impacts. The increase of 'climate extremes' as discussed within the IPCC works likely will lead to an increase of 'disasters' defined as 'severe alterations in the normal functioning due to hazardous physical events interacting with vulnerable conditions that require immediate emergency response' [2]. In the context of climate change, the disaster risk is the likelihood of disasters, and it is influenced not only by hazard, but also by exposure and vulnerability, where the exposure refers to the presence of systems in which hazard events may occur, while the vulnerability is the predisposition to be adversely affected. That means that the disaster is not strictly associated with the occurrence of the extreme weather (statistically out of the average values), but disaster can occur also in the presence of a non-extreme event. The most important factors influencing the vulnerability are the sensitivity, the lack of resilience and low capacities to cope with/adapt to extremes and non-extremes. Moreover, the scientific literature on these subjects clearly underlines that the climatic risk management has two components: risk reduction (prevention and adaptation actions) and disaster management (immediate response after the disaster) [2]. Starting from these concepts, the new challenges for risk management in agriculture are a better understanding of the disaster risk considering the notions of exposure and vulnerability and, consequently, a re-defining of the policy schemes supporting farmers to cope with climate risk.

For these reasons, the main objective of the study is to give indications through the processing of necessary data to target the measures for increasing their effectiveness. The study has three steps of analysis: a) current policy scheme on risk management in agriculture; b) demand for climate risk management in terms of exposure and vulnerability and c) effectiveness of the current risk management scheme, in both component-risk reduction and disaster management.

All the data used are published by the Ministry of Agricultural Food and Forestry Policies Mipaaf (www.politicheagricole.it). The elaborations are the original of the research project 'Research and technical support on natural disasters, climatic and phytosanitary risks in agriculture and related policies', funded to CREA by the Ministry in the period 2010-2015.

\section{CURRENT POLICY SCHEME FOR RISK MANAGEMENT IN AGRICULTURE}

From the side of policy interventions, the analysis of the international context demonstrates that the diffusion of risk management is based fundamentally on economic tools, primarily insurances, helped by supportive public policies [3-5].

The topic of risk management in agriculture has always been at the margins of the European debate, mainly because of the presence of mechanisms to stabilize the markets. Subsequently, the development of instruments covering production risks have been created individually by interested Member States, not evolving according to common paths [6]. For instance, the European Commission leaves to Member States the choice of criteria to declare the adverse events as 'natural disaster'. With the phasing out of guarantees provided by the Common Agricultural Policy, the issue of risk management has gradually acquired a more important role [7]. The European Commission regulation on rural development policy for the period 2014-2020 acknowledges that the agricultural sector is more vulnerable than other sectors to natural disasters, generating a need of support to farmers [8]. The new regulation introduces financial measures for risk management in agriculture, providing support for adverse events: insurance premium subsidies, mutual funds and an income stabilization tool (art. 36-39).

It is also important to consider the position expressed in the document 'Green Paper on the insurance of natural and man-made disasters' produced by the accompanying the launch of 
'An EU strategy on adaptation to climate change' [9]. A general consideration has to be done regarding the explicit choice of insurance as a tool to manage the risk of natural disasters in a context of adaptation strategy, despite the document also expresses the importance of integrating the natural disaster insurances with prevention measures. However, it clears the orientation to transfer the risks rather than enhancing prevention actions and integrated strategies for adaptation.

Italy has a strong tradition of risk management in agriculture. Since the 1970s, the insurance market has offered single-risk hail insurances with the partial coverage of the 'National solidarity fund for natural disasters in agriculture', reformed in 2004 (decrees n. 102/2004 and n. 82/2008), with the main objective of promoting prevention actions. The types of intervention foreseen are: a) aids for payments of insurance premiums (public contribution up to 80 percent of premiums with a damage threshold of above 30 percent of gross saleable production); b) compensation measures for damages to production, infrastructures and production plants, aimed at helping the economic recovery of farms (more than 30 percent for damages) not covered by insurance. It is important to highlight the foreseen principle of exclusion: it is not possible to give compensations for insurable risks that refer to damages to production and to farm structures (included in the National agricultural insurance plan, approved by decree of Mipaaf). It is only under special conditions that compensations can be approved for insurable risks (art. 5 of legislative decree n. 102/04). The 2004 reform and its evolution highlight the choice to give more importance to insurances, which today cover around 80 percent of the available contributions of the Fund [10]. The most important data describing the insurance system are here synthesized [11]:

1. total public contribution for insurance premiums from more than 150 million euros in 2005 to more than 250 million in 2013;

2. total public contribution for compensations from 100 million euros in 2005 to less than 20 million in 2013;

3. the pluri-risk insurances linked to adverse meteorological conditions have had a significant diffusion (almost 46 percent of the insurance market in 2013);

There is a slow positive trend in time of insured production until the 6.4 billion euros of 2014, with correspondent quite low value of indemnified value (300 million in 2014).

The geographical distribution at provincial level (NUT3) of insurance data gives some other elements for reflections (Fig. 1). The insured values are higher in the North and the Centre of Italy (70-80 percent of the contracts), while the indemnified values have a more heterogeneous distribution, but always higher in the North.

These data confirm the results of several previous studies done on the Italian risk management system for agriculture [12-14], showing some critical points, in particular the value of insured base, considered to be excessively low (approximately 18 percent of national production) despite significant public contributions, and the low attractive capacity in the Southern farms.

For the period 2015-2020, a new phase has been open with the EC regulation 1305/2013 on rural development. The Italian Ministry decided to activate the measures for risk management at the national level within the Rural Development Programme (National) [15], with contributions mainly for insurances. The contribution will be 715.860 million euros in the period 2015-2020 (almost 120 million per year). 


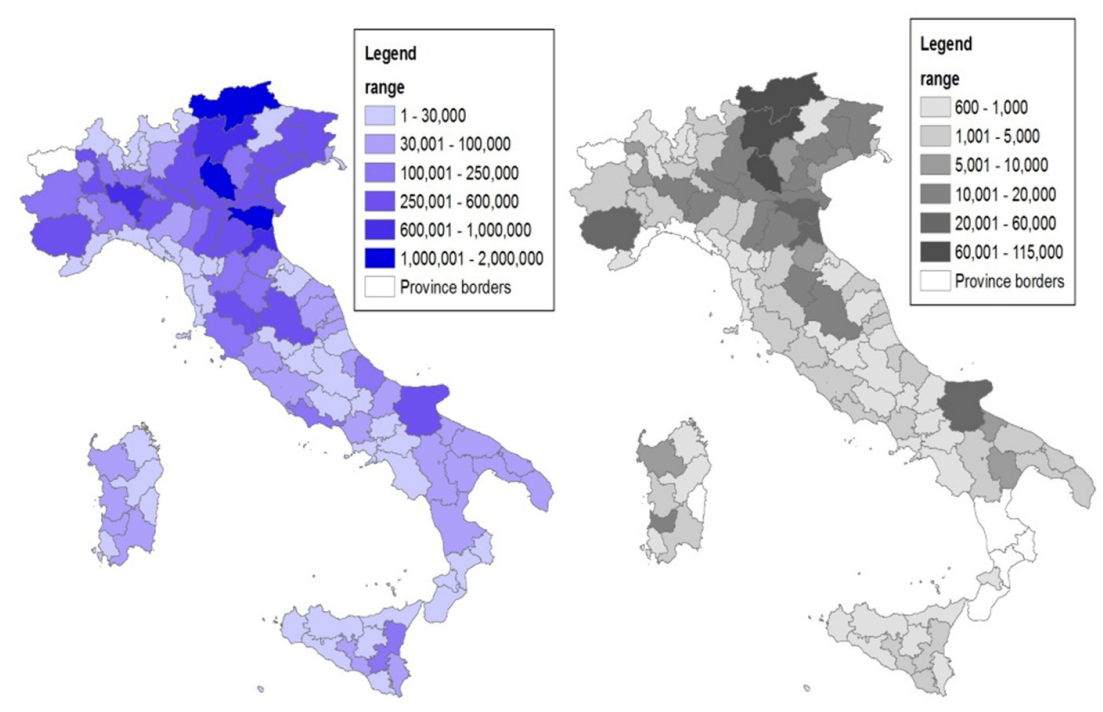

Figure 1: Map of insured (left) and indemnified (right) values 2010-2014 (,000 euros).

In the same policy context, we analysed all the measures of the approved Regional Rural Development Programmes (21 in Italy, www.reterurale.it), looking for actions dedicated to risk reduction and/or adaptation to climate change. The analysis shows that in the objectives, focus areas and measures, the component of risk reduction and the adaptation simply do not exist in the Italian Rural Development Programmes, either any attempt of integrating some structural or management actions with the National measure of risk management dedicated exclusively to the financial tools.

\section{ANALYSIS OF EXPOSURE AND VULNERABILITY}

\subsection{Methodology and dataset}

In the present study, the term 'disaster' is used for adverse climatic events declared by the Italian State as natural disasters in agriculture. The general criteria used by Mipaaf are the threshold of damages (30 percent of average gross saleable production) and the statistical exceptionality of the event (not the same in the previous 5 years in the same territory), but each case can be differently evaluated.

In the research project, a geo-spatial database has been created collecting the official data of Mipaaf from the decrees of declarations of natural disasters in agriculture for the compensation contributions (see par. 1). The decrees report the timing of the event, the location at the level of municipalities and the declared economic damages. Therefore, in the study, we had the opportunity to analyse in a geo-spatial environment physical and economic data from the same source. The database includes data from the 1980s on:

1. Single disasters grouped in the following categories: Extreme snow event, Frost and hoarfrost, Hail, Heavy and prolonged rain leading to flooding, drought, tornado and strong winds, high temperature;

2. Date of the event and/or period of occurrence; 
3. Municipalities and related utilized agricultural area (UAA) declared affected;

4. Declared economic losses on production, farm structures or infrastructure connected to agricultural activities (mostly collective drainage and irrigation channels, rural roads, etc.); the calculation is based for production on UAA involved and official prices at the time of the event of the affected crops, while for structure and infrastructures on the kind of physical damages and the price of rebuilding it. The damage declared does not correspond to the public contribution given for compensation that depends on the financial annual availability of the Fund (see par. 1).

The period considered for this study is 2005-2014. The geographical unit for the territorial analysis is the Province (NUT3, administrative sub-units of Regions).

The choice of indicators is based on IPCC scientific work on indicators, impacts and risk management under climate change [2] and other major related studies [16], with some necessary choices due to the available official data at the National level and the peculiarities of agricultural sector. The indicators chosen are:

1. Exposure: number of days or number of events (depending on the kind of);

2. Vulnerability: $€ /$ ha*days of economic damages, normalized to the exposure and the UAA: (Total damages caused by all the events of the year)/(UAA involved in the events of the year)*(Number of days of exposure to the events of the year). The indicator is presented in the maps as mean value of the period 2005-2014.

\subsection{Analysis of data}

The analysis of data shows a huge amount of total damages in the period 2005-2014, more than 9.285 billion euros, which means an average of 928 million euros per year (Table 1 ). The first consideration is that these damages are a 'demand' for risk management, because the law itself requires that the declaration excludes who are covered by insurances. Moreover, in par. 1 it is reported the level of public contribution given for compensations, far away from the amount of declared damages.

Some more specific considerations emerge about the kind of events and the related damages:

Table 1: Damages declared.

\begin{tabular}{lrcrc}
\hline & \multicolumn{3}{c}{$\begin{array}{c}\text { Damages declared 2005-2014 } \\
\text { Category of event }\end{array}$} & \multicolumn{3}{c}{ (in euro) } \\
\cline { 2 - 4 } & Production & Structures & Infrastructures & Total \\
\hline Extreme snow event & 45,266 & 559,533 & 52,718 & 657,517 \\
High temperatures & 655,101 & & & 655,101 \\
Hail & 30,952 & 36,180 & 2,733 & 69,865 \\
Frost and hoarfrost & 367,386 & 165,896 & 9,284 & 542,566 \\
Heavy and/or prolonged & 989,711 & $1,099,832$ & 988,020 & $3,077,563$ \\
rain leading to flooding & & 15,963 & 1,860 & $3,828,235$ \\
Drought & $3,810,412$ & 142,660 & 2,620 & 153,587 \\
Tornado & 8,307 & 69,843 & & 300,884 \\
Strong winds & 231,041 & $2,089,907$ & $1,057,235$ & $9,285,318$ \\
Total & $6,138,176$ & & & \\
\hline
\end{tabular}


1. The great part of damages is caused by drought and by heavy and/or prolonged rain leading to flooding (41 and 33 percent), followed by extreme snow and high temperatures (both 7 percent);

2. 66 percent refers to the productions, 23 percent to farm structures and 11 percent to infrastructures;

3. The damages to production are mainly due to drought (62 percent) and to heavy and/or prolonged rain leading to flooding (16 percent);

4. The damages to farm structures are mainly due to heavy rain (53 percent) and extreme snow (27 percent);

5. 93 percent of damages to infrastructures are caused by heavy and/or prolonged rain leading to flooding.

As previously explained, the data have been analysed also in relation to the geographical distribution to give indications in the process of targeting measures. That is the reason why this part of the analysis has been done separately for the 2 major events leading to disasters, drought and heavy and/or prolonged rain leading to flooding.

Starting from drought, it is clear that this risk is the most important extreme event affecting the agricultural sector in Italy. Referring to the time distribution, drought events seem to recur with a high severity every 4-5 years (in the period, the most severe occurred in 2012, with 68 percent of the total damages over the 10 years). The spatial distribution of exposure shows the highest values in the North and the Centre, ranging from 201 to 500 days of declared drought (Fig. 2). The map of vulnerability confirms the recent problems in some areas in the North, while in some particular situations in the South the range does not correspond to the level of exposure (lower).

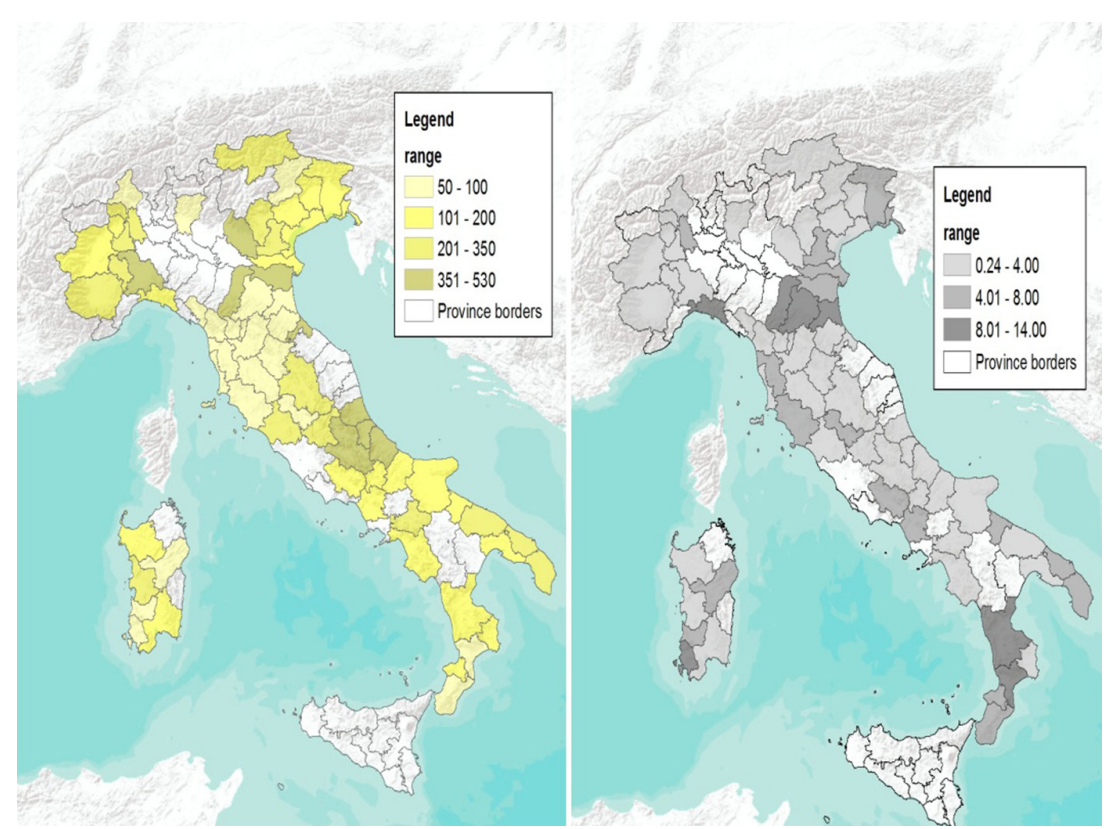

Figure 2: Maps of exposure (left) and vulnerability (right) to drought in 2005-2014 (n. days). 

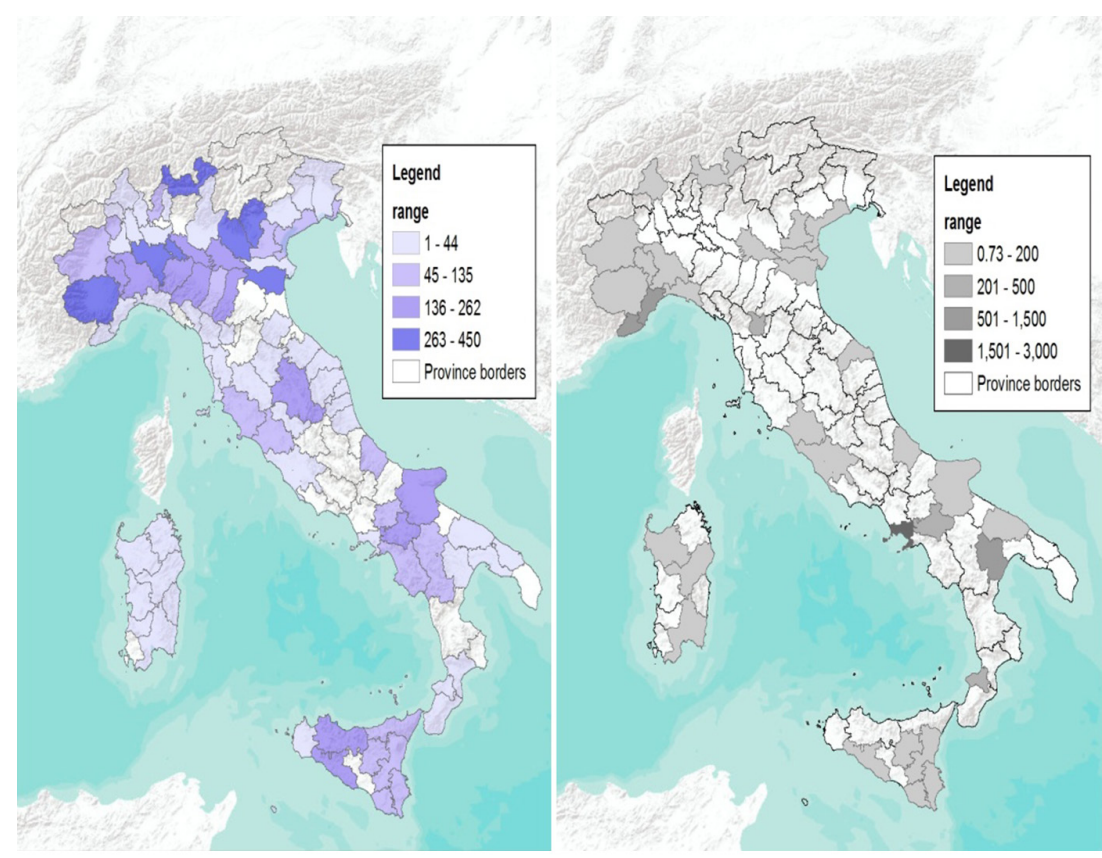

(a)

(b)

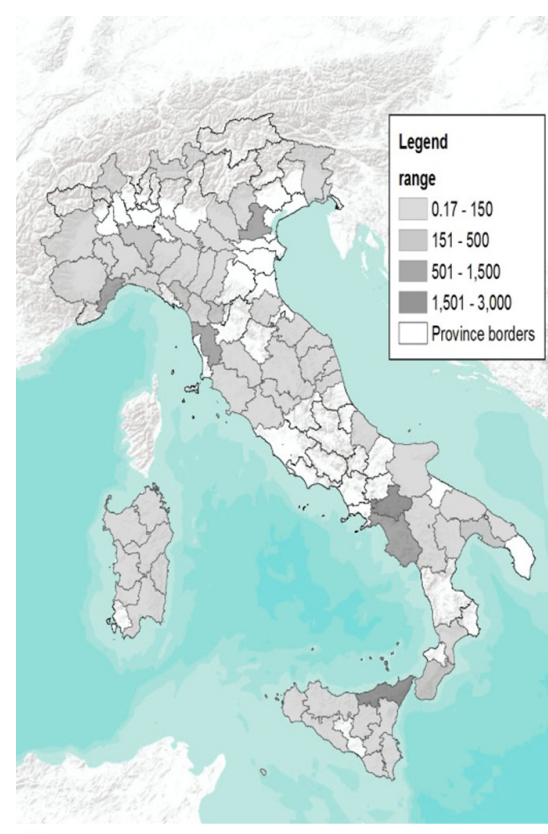

(c)

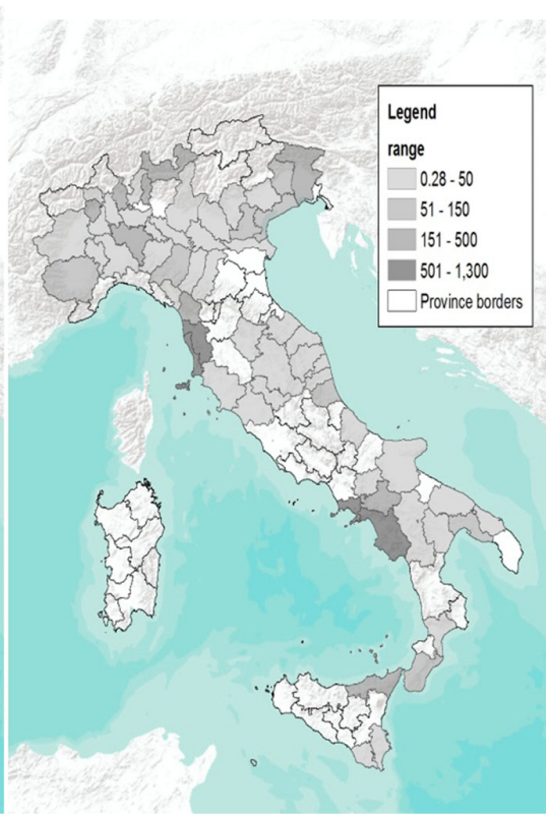

(d)

Figure 3: Exposure and vulnerability to heavy rain in 2005-2014. (a) Exposure (n. days), (b) Vulnerability - productions and (c) Vulnerability - farm structures (d) Vulnerability - infrastructures. 
Referring to disasters caused by extreme events of rain and flooding, in the last decade they have occurred each year, affecting more and more the agricultural activities. The areas most exposed are in the North of Italy, with many provinces ranging from 136 to 450 days of declared state of natural disaster (Fig. 3a). Some areas are also present in the South and the data for Sicilia seems quite anomalous (semi-arid climate). The analysis of vulnerability has been done per kind of damages, because of very different values of the damages to productions (Fig. 3b), structures (Fig. 3c) and infrastructures (Fig. 3d). The highest values of the indicator refer to the farm structures, in term of absolute values and spatial distribution, followed by the infrastructures. Therefore, the great part of agricultural territory has significant 'structural' vulnerability to heavy and/or prolonged rains and floods, with some areas being particularly vulnerable (range 1,500-3,000 euros/ha a day).

\section{POLICY SCHEME EFFECTIVENESS}

Given the results previously illustrated, the third step of the study has been to assess the adequacy of the current Italian risk management policy scheme to the demand for risk management emerging from the exposure and vulnerability of agricultural areas. The assessment is based on qualitative interpretation of data, overlapping the main results and the data on current policy scheme. It is foreseen for future researches the search for a unique indicator of effectiveness, matching different data and climate scenarios, but some important considerations can already be done.

The first element emerging is that the policy scheme stakes all on financial tool of insurances, although the comparison of the absolute values of the current insurance scheme (almost 120 million euros of contributions per year) and the damages declared (almost 928 million euros per year) clearly shows a very high demand for risk management not covered by the insurance system. In the current scheme, the damages should be covered by compensations, whose contribution, however, is decreasing more and more in the last decade (less than 20 million per year) in favour of insurances. At the opposite, the maps of exposure and vulnerability seem to ask for a stronger role for compensation funds in relation to the extreme events that have occurred. For these reasons, it seems that a different strategy should be designed to allocate more effective investments.

This issue on the ability of the insurance system to satisfy the exact needs of the agricultural sector is highlighted also crossing the data of the insured productions and the indemnities, whose values are too low in relation to the mean values of damages.

Furthermore, the main kinds of damages are on productions and farm structures, objects of the Insurance plan. That means that the special cases of derogation to the law in the principle of exclusion are widely applied. To confirm this point, the spatial distribution of the most vulnerable areas often overlap the areas with higher insured productions.

Further considerations useful in designing policy measures refer to the kind of damages. The exposure and the vulnerability to drought is the highest on productions, and the risk appears widespread at territorial level and high in terms of damages, so that the financial coverage of damages is insufficient. Therefore, it seems requiring a different and long-term, adaptation strategy (e.g. investments for irrigation).

The events of rain/flooding hit more structures and infrastructures. Referring to the infrastructures (only in compensation funds), they are often collective and used by entire rural communities, therefore, it seems necessary to apply a territorial approach to risk 
management. Some reflections should be done also on the significant exposure and vulnerability and the frequent occurrence in time that emphasizes a general 'structural' vulnerability of the agricultural areas all over the country to the events of heavy rain and floods. These factors mean that the strategies of transferring or accepting the risks are not sufficient to protect farmers. There is no doubt that insurance is useful to farms in the presence of unforeseeable and extreme events, however, it is important to highlight that it cannot itself represent the only answer. Moreover, the values of damages make the necessary contributions needed for public intervention unaffordable. Instead, the amount of damages shows a strong need for prevention and maintenance actions at the territorial level, which seems to be a prerequisite for any further actions. In this context, tools like mutual funds could be more effective, but, most important, an integrated strategy of reducing exposure and vulnerability of the territory should be programmed, for instance through other measures of Rural Development Programmes, although in the Italian ones there are no trace of risk reduction and adaptation actions. Several other studies confirm that interventions on the components of risk reduction, vulnerability reduction and adaptive capacity are crucial to face risk in the context of adaptation to climate change $[17,18]$, but about this issue some contradictions are also present in the European policies, because of the choice of enhancing insurances and, in the mean time, fixing strict rules and low level of public investments for the policies of austerity.

\section{CONCLUSIONS}

The study indicates that the current Italian policy scheme on risk management needs some important reviews, making more and more strategic the definition of a policy on climatic risk management more complete and effective.

There is a lack of risk analysis in designing policies, oriented more to the market supply (insurances) than to the demand, while the exposure and vulnerability of the agricultural areas are quite high and diversified. This tendency creates an ineffectiveness of policy, but also of the insurance system, that could be more effective in its natural context of catastrophic risk.

The maps of exposure and vulnerability give further indications on the heterogeneity of conditions, to be faced choosing a 'kit' of several measures (economic, structural and managerial) and targeting them in relation to the main factors that differentiate exposure and vulnerability (where, to what kind of disasters and what kind of damages). At the opposite, no targeting is made up in the policy scheme, which, in fact, is based on a single measure at the national level.

As other scientific works are on risk management policies schemes, this study highlights the need of an integrated risk assessment strategy, with critics on the one-solution scheme based on economic tools, mining indeed the important role they could have for the catastrophic risk.

In order to contribute to policy design, the research should also improve the scientific knowledge on the climate issues, giving stronger bases for the definition of disaster risk in the new scenarios, so that we can assess disaster management (for exceptional conditions) and risk reduction and adaptation strategies (for new climate patterns). Moreover, it is important to improve the analysis on policy effectiveness, with multidisciplinary and innovative methods to elaborate in common indicators with climate data and models, geostatistics and policy analysis, expected to give more adequate indications to decision makers and farmers. 


\section{REFERENCES}

[1] Intergovernmental Panel on Climate Change, Climate Change 2007: Impacts, Adaptation and Vulnerability. Contribution of Working Group II to the Fourth Assessment Report of the Intergovernmental Panel on Climate Change, IPCC Geneva, 2007.

[2] Intergovernmental Panel on Climate Change, Managing the Risks of Extreme Events and Disasters to Advance Climate Change Adaptation. A Special Report of Working Groups I and II of the Intergovernmental Panel on Climate Change, Cambridge University Press, Cambridge, UK, and New York, NY, USA, p. 582, 2012.

[3] Bielza Diaz-Caneja, M., Conte, C.G., Dittmann, C., Gallego Pinilla, F.J. \& Stroblmair, J., Agricultural Insurance Schemes, Joint Research Centre Ispra, 2009.

[4] Mahul, O. \& Stutley, C., International experience with agricultural insurance: findings from a world bank survey of 65 countries. Government Support to Agricultural Insurance: Challenges and Options for Developing Countries, The World Bank Washington DC, 2010.

[5] Organization for Economic Co-Operation and Development, Managing Risk in Agriculture: A Holistic Approach, OECD Paris, 2009.

[6] Capitanio, F. \& Cioffi, A., Gestione del rischio in agricoltura ed intervento pubblico. Evoluzione, sostenibilità e prospettive del sistema italiano. Economia e Diritto Agroalimentare XVI, 3, pp. 395-410, 2011.

[7] European commission, Commission Staff Working Document on Risk and Crisis Management in Agriculture SEC (2005) 320, Bruxelles, 2005.

[8] European commission, Regulation (EU) n. 1305/2013 of the European Parliament and of the Council of 17 December 2013 on Support for Rural Development by the European Agricultural Fund for Rural Development, 2013.

[9] European commission, Green Paper on the Insurance of Natural and Man-Made Disasters (Strasbourg, 16.4.2013 COM (2013) 213 final), 2013.

[10] Razeto, G., Assicurazioni agricole agevolate. L'evoluzione del mercato, ISMEA Roma, www.ismea.it, 2014.

[11] Razeto, G., Campagna assicurativa (2010): un primo bilancio, Atti del Convegno Assicurazioni e gestione del rischio in agricoltura: nuovi strumenti ed innovazioni operative, Perugia 26 gennaio, 2011.

[12] Capitanio, F., Bielza, M., Cafiero, C. \& Adinolfi, F., Crop insurance and public intervention in the risk management in agriculture: does farmers really benefit? Applied Economics, 43(2), pp. 4149-4415, 2011.

http://dx.doi.org/10.1080/00036846.2010.487823

[13] Cafiero, C., Capitanio, F., Cioffi, A. \& Coppola, A., Risk and crisis management in the reformed european agricultural policy. Canadian Journal of Agricultural Economics/ Revue canadienne d'agroeconomie, 55, pp. 419-441. http://dx.doi.org/10.1111/j.1744-7976.2007.00100.x

[14] Pontrandolfi, A., Capitanio, C., Enjolras, G. \& Goodwin, B., Analysis of demand for climatic risk management tools in agriculture in Italy. PAGRI/IAP n. 3/2014, eds. L'Informatore agrario Verona, printing 2014.

[15] Ministry of Agricultural Food and Forestry Policies, Rural Development Programme (National) approved with EC decision (C2015) 8312 of 11/20/2015, www. politicheagricole.it, 2015

[16] Fellmann, T., The assessment of climate change-related vulnerability in the agricultural sector: reviewing conceptual frameworks, Building Resilience for Adaptation to Climate 
Change in the Agriculture Sector Proceedings of a Joint FAO/OECD Workshop, FAO Roma, ISBN 978-92-5-107373-5, 2012.

[17] Smit, B. \& Wandel, J., Adaptation, adaptive capacity and vulnerability. Global Environmental Change, 16, pp. 228-292, 2006.

http://dx.doi.org/10.1016/j.gloenvcha.2006.03.008

[18] Reidsma, P., Ewert, F., Lansink, A.O. \& Leemans, R., Adaptation to climate change and climate variability in European agriculture: the importance of farm level responses. European Journal of Agronomy, 32, pp. 90-102, 2010.

http://dx.doi.org/10.1016/j.eja.2009.06.003 